\title{
Role of Organisational career websites for employer brand development
}

\begin{tabular}{|r|l|}
\hline Journal: & International Journal of Organizational Analysis \\
\hline Manuscript ID & IJOA-01-2018-1327 \\
\hline Manuscript Type: & Original Article \\
\hline Keywords: & $\begin{array}{l}\text { Organizational websites, Career Development, employer branding, } \\
\text { Strategic management, talent relationship management, Brands }\end{array}$ \\
\hline \multicolumn{2}{|l}{} \\
\hline
\end{tabular}

\section{SCHOLARONE ${ }^{\text {Mx }}$ \\ Manuscripts}




\section{Role of organizational career websites for employer brand development}

\section{Introduction}

The burgeoning of social media in the talent market has been found to prompt potential talent pools to consider the employer brands of their prospective employers by visiting websites such as Glassdoor.com, Salary.com and Payscale.com when making initial applicant decisions based on salaries and company ratings (Tanwar and Prasad, 2017). Besides, ever since, the internet has become the window to the world for all banks operating in emerging market contexts and from an image management standpoint (Hinson et al., 2010), corporate recruitment websites in turn are being perceived as an effective tool banks can use to position themselves as employers of choice through the design and communication of authentic employer branding (EB) strategies (Martin et al.,2011).Consequently, survival in the current context of financial turmoil, calls for the crucial need to have a strong and differentiated employer brand (Bravo et al., .2012). Furthermore, the enthusiasm for research and practice of EB by organisations has spread drastically worldwide recently following the global financial crisis (GFC) where EB became the vital main concern of the top management team. The main objective of EB initiatives have been on talent attraction strategies throughout the financial growth period. Yet, with the cutback in staffing and headcount following the GFC, organisations transferred their attention to engagement and retention of the existing talent pool. Consequently, the economic recession has in fact had positive influences on the adoption of EB as organisations are actually recognizing the real advantages of EB as the key driver of talent attraction, engagement and retention strategies (Minchington, 2010).

Despite the takeoff of internet recruitment research (Backhaus, 2004; Lee, 2005; Kroustalis and Meade, 2007) not much has been debated regarding the career website as the communication vehicle of the employer brand. In fact there exists a paucity of available literature on the views of HR professionals on the use of the web for communicating the employer brand. Nevertheless, Bondarouk et al., (2013) has focused on analyzing the perceptions of HR professionals regarding the impact of social media on employer branding. However, the views of HR professionals regarding the dissemination of the employer brand through career websites have not yet been well researched.

As a result to address this significant gap in the literature this study embarked on a journey to investigate the use of career websites to publicize the employer brand for sustainable strategic relationship management (STRM) having as research context the Mauritian Banking Sector 
(MBS). It is a known fact that winning the war for talent in tight labour market conditions across the globe, especially in the banking sector post GFC is the current dilemma being experienced by many banks as an aftermath of the Barclays controversy regarding highly remunerated senior HR positions (Jenkins and Goff, 2012). Consequently, the role and responsibility of the Human Resource function in winning the talent battle through the use of HRMarketing (WelsingBoogard, 2006; Jothi, 2010) more specifically branding principles has become a must and a necessity given that branding the organization as an employer is not the same as branding it for external customers. However, many employers more specifically senior management and HR practitioners seem perplexed when their views about their respective employer brands are solicited (Universum global, 2014).

Therefore this qualitative study makes an attempt to address the existing gap in the literature regarding the utilization of the career website to broadcast the employer brand within the MBS. The core values of the Mauritius Bankers Association (MBA) revolve around an innovation culture resting on strong work ethics and team work achieved through the employment of qualified and dedicated staff. Besides, in line with the honesty and integrity core values, employees are assured to be treated with respect and dignity (Mauritius Bankers Association, 2014). Accordingly, HR professionals of the MBS were considered to be the most appropriate informants to enlighten the academic and practitioners community regarding the communication of the employer brand for STRM using banks' corporate recruitment websites. Therefore the main purpose of this paper is firstly to investigate the use of career websites in the Mauritian banking sector for disseminating the employer brand and secondly to explore the communication of total rewards as part of the employer branding strategy on banks' career websites.

\section{Theoretical background}

Employer branding is perceived as a precious determinant of strategic organisational competitive advantage, designed not only to attract the finest talent from the external talent pool but also to engage and retain the internal talent pool (Kucherov and Samokish, 2016). The origins of employer branding are linked to the internal marketing concept such that "Employer branding has been viewed as a pre mature and underdeveloped component of internal marketing and employer attractiveness, whereby the latter denotes the potential benefits envisaged by the external talent pool as prospective employees" (Berthon et al., 2005, p.151). Consequently, the heart of the EB concept has been portrayed as the power "to attract better 
candidates, as it helps them picture themselves as being a part of the corporation whereby, by using employer branding, companies show how they differ from their competitors and why the best applicants should choose to work for them" (Bondarouk et al., 2013 p.27).

EB has also been described as a calculated long-standing stratagem designed to attract, engage and retain talent (Minchington, 2009). In this context, Scialpi (2016) has taken a HRMarketing stand regarding EB as fundamentally a Marketing Strategy applied to Human Resources such that just as companies realize marketing and communication activities to attract and retain high value clients, communication and marketing strategies are deployed to attract, engage and retain high value people for effective organizational performance. However as argued by Bondarouk et al., (2013), EB is much more than the people within an organization, as it is a complete practice put in place to enhance the corporate image of the company as an employer of choice to current and potential talents. As a tool to gain competitive advantage, EB is also looked upon as a long-term strategy to construct an authentic and attractive employer personality to handle the opinion of future and existing talents (Bondarouk et al.,2013).In addition it has been reported by (Oladipo et al., 2013) that the incapability of HR practitioners to design effective Human Resource policies, practices and strategies to attract, engage and retain scarce talent has triggered the birth of EB which is still undergoing a steady progress and attention around the globe. Nevertheless, numerous companies have still not yet totally appreciated the value of adopting EB initiatives. Drawing from earlier studies conducted by (Cable and Turban, 2001), Baum and Kabst (2014) have recently thrashed out three fundamental aspects of employer knowledge which they describe as the employer brand.

The first aspect 'familiarity with the company', sheds light on the ease with which a prospective job applicant can spot an organization as a potential employer, based on its corporate image and reputation (Gatewood et al., 1993; Cable and Turban, 2003; Collins, 2007; Chunyan et al., 2015). Furthermore, the second element concerns employer reputation, portraying the prospective applicants' perceptions of the organisations' employer of choice status. Finally, the third aspect of job information depicts individual applicants' perceptions of accuracy in job and organizational characteristics such as the career opportunities provided by the corporation, pertaining to information provided in job previews, job advertisements and career websites. As a result talent attraction is determined by the information conveyed in the employer brand.

Given that nowadays corporations have a plethora of channels to communicate their employer brand and to recruit from, it is primordial to assess which channels provide the best return on 
investment based on recruiting objectives. The use of social media to communicate the employer brand has also been found to consolidate the corporate reputation of the entity (Siverentzen et al., 2013; Ladkin and Buhalis,2016), given that social media information about potential applicants are a useful means to predict person-organization fit (Van Iddekinge et al.,2016). Nevertheless, the real benefits of social media on talent attraction would only be reaped through the design and communication of an authentic employer branding strategy (Priyadarshini et al.,2017).Besides, despite social media being described as the main activity being undertaken by companies to enhance their employer brand, career website development continues to rate highly along with recruitment advertising, employment marketing and recruitment branding (Minchington, 2014; Novak,2017). Thus a study conducted by Minchington (2013; 2014), revealed that $20 \%$ of potential applicants considered organisational career websites as their preferred recruitment channel. Besides, potential applicants are increasingly being attracted by career websites such that more than $97 \%$ of job seekers explore job opportunities by accessing employers' corporate recruitment websites (Singh, 2017)

\section{Career websites}

Potential applicants have a tendency to critically scrutinize employment related information provided on career websites to determine organizational attractiveness (Hu et al., 2009; Ladkin and Buhalis,2016). However, despite being the most usual channel and touchpoint recently, online recruitment has not yet positioned itself as the leading recruitment method (Parry and Wilson, 2009; Singh, 2017). This may be attributed to the fact that it is still perceived to be depersonalized given that there are some reservations concerning the handling of the process and the integrity of the job advertisements (Brando et al., 2017). In spite of this, based on previous research conducted by (Landers and Schmidt, 2016; McDonald and Thompson, 2016), Hooley (2017) posits that organizations as employers are making considerable use of the internet for the purpose of talent attraction in the recruitment and screening of potential job applicants. Furthermore, a thorough scrutinization of the top ten Forbes listed Saudi corporate websites by Khan (2017) revealed that potential talents were attracted by organizations having attractive corporate and career websites. Likewise, commercial banks are making use of career websites to portray the banks' specific employer image such that an online search of banks' career websites disclose unique arrangement of information targeted at the talent market (Amine et al., 2013). 
Career websites have been designed for communicating both the employer and internal branding strategies such that major banks from the global banking industry for instance have a web link dedicated to training and orientation as key components of their career websites (e.g.goldmanscahs.com; Baraclays.com). Furthermore, research in the field of e-recruitment suggest that the nature of information available on organization websites and career web pages has a strong impact on potential applicants perceived person-organization fit and person job fit as well as intention to apply (Gardener et al., 2012; Scialpi,2016). Similarly, it has also been reported that development and career related information of job previews displayed on career websites normally triggers inquisitiveness and delight amongst potential applicants (Priyadarshini et al., 2017). In the same way, several studies have been conducted to analyze talent attraction to organisations' career websites (Williamson et al., 2003; Backhaus 2004; Williamson et al., 2010; Walker et al., 2009; Cable and Yu 2006; Lievens, et al., 2007). However, the majority of these studies have either focused on fictitious websites or sectors, but not yet on a specific sector thus giving rise to a research gap which the present study aims to address by targeting the banking sector. An examination of corporate recruitment websites of familiar banks such as Goldman Sachs, Barclays, and HSBC in the global sectors has disclosed the existence of a career corner directing potential applicants to relevant information regarding the work environment, realistic job previews including rewards, benefits as well as development opportunities.

Additionally, the literature on e-recruitment highlights the existence of three main purposes of career websites namely recruitment orientation, screening orientation and dual purpose orientation (Williamson et al., 2003). The use of screening orientation has also permitted the attraction of higher quality talent pools for actual web-based job advertisements due to the provision of precise information to support potential applicants to self-evaluate and self-screen their fit to the job position (Dineen and Williamson, 2012).

Another gap in the literature is identified at this point, since general studies have been carried out on commercial banks' corporate websites (Bravo et al., 2011, 2012; Amine, 2013) with few studies on career websites across sectors (Backhaus,2004;Zamparini et al., 2010) but not specifically in the banking sector. Certain studies relied on fictitious career websites (Williamson and Lepak, 2003; Walker et al., 2009; Lievens et al., 2007; Thompson et al., 2008; Priyadarshini et al., 2017) whereas others relied on real company websites mostly fortune best places to work (Lee, 2005; Braddy et al., 2008; Young and Foot 2005; Cober et al., 2004). 
Generally, the key informants of these previous studies have been undergraduate and graduate students at specific universities who have been answering to survey questions in computer labs either after or while viewing specific career websites (Cable and Yu 2006; Williamson and Lepak, 2003,Marcel et al., 2008).Regarding the impact of the content of career websites on talent attraction, previous research has indicated the positive effects of communicating compensation, career information in realistic job previews either using traditional or web recruitment methods on initial talent attraction (Cober et al., 2003). Former studies have also widely employed content analysis as the main tool to scrutinize corporate websites (Srivasta et al., 2009) as well as corporate recruitment websites (Lee, 2005, Backhaus, 2004).However, a dearth of relevant research portraying the views of HR professionals on the use of career websites to communicate the employer brand is evident. Having provided an overview of the contents of career websites, the next section focuses on the total rewards components aspects of the employer brand displayed through career websites to address the second research objective of the study.

\section{The Total rewards component of the employer brand and career websites}

Based on an empirical study conducted in the Indian IT sector, Tanwar and Prasad (2017) strongly recommend the incorporation of compensation, benefits, development and career opportunities as well as work life balance, the four key components of the total rewards strategy as core elements of the employer brand to assist organizations in facing the challenges involved in the attraction, engagement and retention of talent.

Likewise, the incorporation of the total rewards components in the employer brand has recently been proposed to enable organizations to differentiate themselves in the competitive talent market to win the ever tough war for talent (Schlechter et al., 2015). Hence the need to communicate the total reward components as part of the EB strategy becomes a leeway to harness authenticity. Besides, the notion of authentic voice engendered by Harquail, (2009) has been put forward by (Martin et al., 2011) to sustain the uniqueness of the employer brand since "authentic voice refers to the expression of self identity created when people are empowered to speak the truth about themselves, when they tell us what they know about themselves, when they are allowed to argue for what they care about, when they tell the world how they see things from their unique perspective and when they argue for their own wisdom, in their unique way" (p.14). Correspondingly, a comparison of the contents section of Cober et al., (2004) career website dimensions displaying employment related information show the presence of the five 
total rewards components which is illustrated by compensation, salary, benefits, work life, performance and recognition exemplified by employee testimonials and profile of star employees and finally development and career opportunities which is accounted by the training aspect proposed by Cober et al., (2004).

Moreover, a study carried out by the world at work association on EB and total rewards in (2010) has revealed the capital importance of integrating total reward as a core element of the employer brand for the purpose of differentiation in the talent market. The study further discloses the emptiness state of an employer brand in the absence of the total reward component as the authentic stuffing. In contrast a total reward oriented employer brand embellishes the employee value proposition rendering the employment relationship deal underlying the psychological contract more meaningful. In addition many employers aspire to align total reward to the employer brand to guarantee that they uphold to the promise of positioning the organisation as a great place to work, to eventually sustain talent engagement as part of the STRM process (CIPD and Mercer, 2010).

The literature synthesis can be concluded with the following conceptual framework as displayed in figure 1. The conceptual framework portrays the employer brand depicting the total rewards components which matches the employment related information of Cober et al.,(2004) career website dimensions. The conceptual framework also illustrates the ultimate purpose of EB, "STRM" achieved having as vehicle the career website.

\section{INSERT FIGURE 1 HERE}

\section{Research context and Methodology}

This research adopted a case study approach with the aim of examining a particular phenomenon the employer brand disseminated through organisations' career websites within a particular context the banking sector (Miles and Huberman, 1994; Yin, 2013). The premise of this paper has been to investigate the utilization of banks' career website to communicate the total rewards components of the employer branding strategy. Likewise, given that the context of the study is the MBS, the career websites of the 21 banks from the MBS were scrutinized to identify the communication of the Towers Watson (2013) total rewards model comprising of compensation, benefits, development and career opportunities, work life balance and performance and recognition as core components the EB strategy. In order to identify the presence of the five total rewards components on banks' career websites, qualitative content 
analysis having as basis the content section of career websites pertaining to employment related information proposed by Cober et al., (2004) was used.

Furthermore, in line with the purpose of this study, the research population comprised of MBS HR professionals who are fully cognizant about employer branding and career websites. The number of interviews was selected using the theoretical saturation method given that the usual premise governing the use of semi structured interviews in qualitative research is that sufficient interviews are conducted till similarities and saturation is reached (Mason,2010; Fusch and Ness, 2015). Previous qualitative studies (e.g.Gilani et al., 2016) reached saturation with a sample size of 12 whereas (Lukea-Bhiwajee and Garavan, 2016) purposive sample comprised of 16 participants. Similarly, Hess and Kelman (2017) gathered their qualitative data from 9 participants in a SIDS context. Likewise, Kemp and Zhao (2016) collected their qualitative data from a sample of only 19 Emirati participants. In the current study, saturation was reached with $27 \mathrm{HR}$ practitioners. As a result, the views of the $27 \mathrm{HR}$ practitioners from the 13 banks who participated in this qualitative study comprising of HR directors, reward managers and talent managers, were gathered through semi-structured interviews which lasted for 60 to 90 minutes. The Mauritian Bankers' Association website was used to obtain the contact details of banks. All the interviews were conducted in English and were digitally recorded with the participants' permission. Additionally, detailed notes were also taken simultaneously during the interviews.

Furthermore, for confidentiality purposes, the banks' real identities have been concealed in the analysis and discussion. As a result, multinational banks having a branch in Mauritius have been referred to as MNE HQ UK for example if the headquarters is located in the UK and MNE $\mathrm{HQ}$ France when the MNE is located in France. The 27 participants have been referred to as $\mathrm{P} 1$ to P27 with the corresponding HR position such as P3 HR manager MNE HQ France. Similarly Mauritian banks have been referred to as MB for example P 15 Group Head of HR MB 6 denoting the sixth Mauritian bank having participated in the study. Table 1 below provides details regarding the job positions of the participants.

\section{INSERT TABLE 1 HERE}

\section{Findings and analysis}

Qualitative data were analysed using the coding method whereby in the first instance concepts and categories related to the content section of career websites as defined by (Cober et al., 2004) were considered as benchmark for the identification of the presence of the five 
components of the total rewards model on banks' career websites. Therefore, the respective career websites of the 21 banks of the MBS were scrutinized having as basis the contents section of Cober et al., (2004) career website dimensions. Consequently, the employment related information depicting the five total rewards components of compensation, salary, benefits, work life, performance and recognition exemplified by employee testimonials and profile of star employees and finally development and career opportunities (Cober et al., 2004) were isolated on the banks' career websites.

Moreover, the semi structured interviews provided further in depth insights on the communication of the total rewards components of the employer brand by the career websites. The interviews were fully transcribed as per standard qualitative techniques (Glaser and Strauss, 1967; Strauss and Corbin, 1998) and data analysis was guided by the Braun and Clark (2006) thematic analysis framework. Key concepts from the literature related to the total rewards contents of the employer brand displayed on banks' career websites were brought to the data for the purpose of coding and data interpretation. As a result, main and subthemes pertaining to the communication of total rewards through the banks' career websites emerged to give shape to the findings. Attempts were made to maximize the rigor element required of qualitative studies (confirmability, dependability, credibility, transferability and applicability) in line with the guidelines provided by (Krippendorff, 2012). Additionally, to amplify reproducibility, the transcripts were coded and analyzed by two research assistants separately. Consequently, the codes and corresponding quotations were analyzed and organized into relevant themes. Following the coding exercise, the researchers compared and discussed the differences in findings and interpretations. The findings on which the researchers disagreed were omitted as recommended by (Ballafkih et al.,2017).

Furthermore, the guidelines of "pattern matching" and comparative methods to draw conclusions (Yin, 1994) assisted in the consolidation of the findings. Patterns were detected from the interview transcripts through the thematic analysis process, which subsequently uncovered three main themes:

- The employer brand communicated by MBS banks' career website

- The need for career website revamping

- Career websites displaying total reward component of the employer brand

These themes derived from the thematic analysis process are displayed in table 2 below. The pattern matching exercise carried out with sample relevant text extracts supporting the 
corresponding themes is also clearly demonstrated. The integral text extracts have consequently assisted in the in depth discussion of the findings.

\section{INSERT TABLE 2 HERE}

\section{Discussion}

\section{The employer brand communicated by MBS banks' career website}

MBS HR practitioners confessed that presently their respective banks' career websites can be mostly categorized as being recruitment oriented (Williamson et al., 2003). Nevertheless the desire to upgrade to screening orientation for effective STRM is in the pipeline. Moreover according to the rewards and benefits manager at MB6, all jobs are advertised internally first on the intranet and then externally on the career webpage. Nevertheless, the career websites of Mauritian banks is viewed by HR practitioners to be not enough interactive in the absence of employee testimonials, animations and videos. Therefore, HR practitioners want more effort to be exercised by their team to portray the employer brand on their respective career websites. Some relevant affirmations made by $\mathrm{HR}$ professionals such as $\mathrm{P} 17 \mathrm{HR}$ operations manager at MB 6 and P20 Talent management specialist at MB 6 can be observed from table 2 above.

In the same way, P19 the HR services manager at MB6 appeared worried that the actual career website is not very effective in communicating the employer brand. He believed that it needed to be more dynamic and interactive with more vibrancy by including employee testimonials. He also proposed adding a section for applicants to answer questions and obtain a prompt reply thereby facilitating self-selection (Ryan et al., 2000) and job,organization,brand and culture fit objectives as suggested by existing literature (kristoff- Brown, 2000; Hurell and Scholarios, 2013).

Consequently, HR professionals suggested placing more emphasis on screening orientation while at the same upgrading the interactivity element of the function section of the career website. Similarly, participants revealed that the global career websites reflect the employer of choice status of the MNEs and portrays the global employer brand as stated by one Head of HR: "The group career website tries to portray employer of choice status and the publicizing of employer awards. However no local career website has been designed to date". P4 Head of HR MNE HQ South Africa 
As a result, no customised local career website reflecting the local employer brand is yet available since the employer brand is still at conceptual stage and once ready it will be displayed on the revamped career website. Other reflections regarding the utilization of the career website for publicizing the employer brand greatly contributed to unearth the views of the HR professionals as can be gleaned from the following statement.

“Internal and external recruitment depend on different communication means. The external career website is carefully formulated, with little and basic information. Communication should aim at engaging talents to the employer brand." $P 10$ HR officer MB 1

The honest communication of the employer brand on the career website was also recommended by HR professionals. The core values of a bank reflecting the employer brand being clearly displayed on their respective career website depicts the type of talents the bank wants to recruit. It further demonstrates organizational culture and prospective brand fit (Bouton, 2015; Hurell and Scholarios, 2013; Nazir 2005; Kristoff-Brown, 2000).

Furthermore, the HR manager of an Indian MNE bank shared that the position of the bank as an employer is well defined and relevant information about the work environment is provided on the career website. In addition, the HR staff also emphasize on the need to provide accurate information on the career website for the employer brand to be effective (Martin et al., 2011), which supports the literature governing the honesty feature of the employer brand as per the signaling theory (Spence, 1973; Connelly et al., 2011; Bangerter et al., 2012;Celani and Singh, 2011).

"The position of the bank as an employer is well defined and relevant information about the work environment is provided on the career website. We need to provide accurate information as honesty is important." P2 HR manager MNE HQ India B

Likewise, the HR officer of a major South African MNE confirms the presence of a career section on the bank's corporate website where the message from the CEO about the bank, the strategy of the bank locally and globally is well communicated. The participant also shared that the communication of the South African graduate program is made simultaneously on the global corporate and career websites. Consequently, the HR department in Mauritius is actually working on a local graduate programme which has been depicted as campus recruiting and internships in previous studies by (Cober et al., 2004). 
"I am fully aware of the career section on the corporate website where the Message from CEO about the bank, the strategy of the bank locally and globally is well communicated. The South African graduate program is available on the global corporate and career website. Consequently the HR staff in Mauritius are actually working on a local graduate programme". P5 HR officer MNE South Africa

In contrast, the vice president of Finance at MB 5 who is responsible for people management at the bank confessed the absence of a career website to communicate the bank's employer brand.

"The bank does not possess a formal career website, however the core values such as ethics is present on the corporate website. The corporate website briefly talks about the values of the bank, however the bank does not have a formal career website or even a link on the corporate website related to career up to now". P 14 Vice president of Finance MB 5

The above statement by the Vice President of finance confirms the crucial role of HR professionals in ensuring that banks as organisations possess a well-designed career website to communicate their respective employer brands for the attraction, engagement and retention of talents. In this particular case it can be deduced that since the responsibility for HR has been attributed to a finance professional, not enough effort is being dispensed to the employer branding strategy itself.

\section{The need for career website Revamping}

Most of the banks are currently in the process of revamping their career websites even though few find it quite accessible in its present attire as confirmed by the rewards manager at MNE HQ UK A who professed that: "The career website needs a lot of revamping. It should be more attractive in terms of employee sharing their experiences and how easy it is for applicants to apply that is in terms of user friendliness. Not all components are present. However, Assignment opportunities, Learning opportunities and the term Competitive remuneration packages are communicated". P7 Rewards manager MNE HQ UK A

As a result, HR practitioners of the MBS have expressed their desire to urgently embark on the revamping journey of their existing career websites. Such a decision would encourage a greater number of potential applicants to apply for job positions. This was captured by the comments made by the Head of $\mathrm{HR}$ at one of the major banks and provides useful insights for consideration by the global HR community. "The revamped career website would reflect the employer branding strategy. It will also exhibit success stories through employee testimonials. 
Career opportunities offered provides the ability to see global opportunities. The total rewards components are not yet displayed. Only general information is available on the local career website, however, the global career website offers more detailed information". P8 Head of HR MNE HQ UK A

In addition the need to include a testimonials section (Walker et al., 2009) on the career page has also been recommended by the Head of HR \& Change of one bank.

Moreover, MBS HR professionals additionally evoked the provision of screening orientation (Williamson et al., 2003) to allow more interactivity as supported by the following text extract:

"The career website needs a lot of revamping. It should be more attractive in terms of employee sharing their experiences and how easy it is for applicants to apply that is in terms of user friendliness." P7 Rewards manager MNE HQ UK A

Furthermore, the HR professionals proposed the idea of having a better display of the employer brand on the career website.

"The career website does not really reflect the employer brand and needs to be revamped and reworded. A simplified job description is available on the career website without providing many details on the total reward components. " P3 HR manager MNE France

"The present career page does not really reflect the EB strategy which is being developed right now. Thus, the career website is being revamped. P 15 Group Head of HR MB 6

The views expressed by MBS HR practitioners regarding the revamping of their respective banks' career websites provide rich insights for the MBS to position itself as the employer of choice amidst the challenges involved in the war for talent.

\section{Career websites displaying the total reward component of the employer brand}

A close analysis of the welcome and opening statements of the career websites of the 21 banks of the MBS reveal the communication of total reward strategy, whereas the content section of career websites disclose only introductory information on the five total rewards components. This fact is further confirmed by the statements made by one HR officer: "Brief mention of worklife balance, performance and career development appear on the career website." P5 HR officer MNE HQ South Africa and one talent management coordinator: "General information on Total rewards is displayed on the career website." $P 24$ Talent management coordinator MB 6 and the 
group Head of HR at a major bank: "The total rewards components have not yet been fully included on the career website." P 15 Group Head of HR MB 6

Moreover, a detailed scrutinisation of the career website content section analysis using the Cober et al., (2004) dimensions, revealed the presence of the Towers Watson (2013) total rewards components which is further confirmed by the following statements from the MBS HR professionals:

"The total rewards components are briefly mentioned at MB1." P 10 HR officer MB 1

"The total rewards components have not yet been displayed in details but in general" $P 17$ HR operations manager MB 6

"Only general information on total rewards are displayed on the career website." $P 23$ Talent management coordinator MB 6

Likewise, despite the concern expressed regarding career website revamping, MBS HR practitioners are still reluctant to fully consider the holistic dissemination of the compensation component of their total rewards strategy on their respective career websites. The main reason being that compensation is still being viewed as 'confidential'. This finding contradicts previous studies by Cober et al., (2004) and Williamson et al., (2003) who recommended the communication of compensation and benefits.

Correspondingly the following statement by the Head of HR of a South African MNE buttresses the current finding from the MBS: "These details about the compensation and benefits components of total rewards are quite confidential and are thus not communicated on the career website" P4 Head of HR MNE HQ South Africa which is supported by the other HR professionals having participated in the study such as the following views expressed by one HR manager:

"Excluding compensation all the other components are present on the career website." P2 HR manager MNE HQ India $B$

In addition, the analysis of the contents of MBS banks' career websites contradict Cober et al., (2004) research findings by straightforwardly providing an overview of the performance and recognition initiatives of the banks.

Furthermore, MBS HR professionals have also voiced out their opinion regarding the inclusion and communication of the total rewards elements as the core foundation of the EB strategy and profess that detailed information regarding the individual components differs across banks 
which according to HR professionals reflect the culture of the bank concerned. As a result, very brief overview has been provided regarding compensation and benefits packages, development and career opportunities, performance and recognition and work life balance.

For instance the career website of MNE HQ UK A displays just "recognition and bonus, retirement benefits, travel benefits", whereas the career website of MNE HQ India B only briefly mentions "attractive compensation and benefits". On the other hand MNE HQ UK B displays "development and career opportunities, recognition as well as work life balance initiatives" on its career website. Likewise, the employer brand communicated by the career website of MB 6 exhibits the bank's “development and career opportunities, recognition, work life balance, compensation and recognition initiatives, while emphasizing on the "handsome rewards" provided as well as the "entrenched performance culture". Nevertheless, all jobs posted exclude compensation details as MB6 wants employees to be motivated by the job not the money. In addition, standardized benefits are communicated on the employee corner for all grades, yet only introductory information about compensation is mirrored on the career website.

In the same way the majority of HR professionals have agreed to the fact that only general brief information about the total rewards components are displayed on the career websites of their respective banks. Some have emphasized on the presence of development and career opportunities, and others on performance and recognition. It is also interesting to note that the Rewards and Benefits manager at a major Mauritian bank confessed that "details about the total rewards components are present only on the intranet and not the career website" implying that the existence of discrepancies regarding the internal branding strategy for internal recruitment and the EB strategy targeted at the external talent pool.

Besides, the HR officer at a South African MNE bank professed that brief details of work-life balance, performance and career development are in fact mentioned on the career website. In the same way the Rewards manager at MNE HQ UK A asserted that assignment opportunities, learning opportunities and only the term "Competitive remuneration packages" are communicated as part of the EB strategy through the career website. Moreover, the Head of HR of the same bank added that in fact the total rewards components are not yet fully displayed and only general information is available on the local career website. However, the global career website offers more detailed information without going into much detail since these are perceived to be very confidential information according to the HR practitioners. The following extract buttress the views expressed by MNE HR professionals. 
"Career opportunities offered provide the ability to see global opportunities. The total rewards components are not yet displayed. Only general information is available on the local career website, however, the global career website offers more detailed information". P8 Head of HR MNE HQ UK A

The views of the MBS HR professionals show their reluctance to provide extant details on the total rewards components of the employer brand on the banks' career websites, which they have attributed to the competitive culture prevailing in the Mauritian talent market. However, as illustrated by figure 1 the conceptual framework, the thematic analysis outcome (table 2) portraying the empirical findings confirm the presence of the total rewards components as a core aspect of the employer brand disseminated through banks' organisational career websites.

\section{Conclusion}

The career websites of Mauritian banks is viewed by HR practitioners not to be enough interactive without employee testimonials, animations and videos. The core values of the banks reflecting the employer brand is clearly displayed on the career website which depicts the type of talents the bank wants to recruit. However, HR professionals would like more effort to be exercised by their team to portray the employer brand on their respective banks' career website. Most of the banks are currently in the process of revamping their career websites even though few find it quite accessible in its present attire. The general opinion shared by MBS HR professionals is to provide equal attention to the form, content and function sections of the career website. Moreover the adoption of a screening orientation on top of the existing recruitment career website orientation would more effectively portray the employer brand. At the same time mixed views are shared regarding the sharing of detailed information about the total rewards strategy specifically compensation and benefits as the core element of the employer brand conveyed via the career websites. The main causes of resistance include the corporate and national culture as well as the need to maintain confidentiality for greater competitiveness to eventually win the talent war.

\section{Theoretical and practical implications}

This study provides rich insights on the communication of the employer brand using organisational career websites from the HR professionals' perspective, an underdeveloped research area to date. The methodology used in previous research (Zamparini et al., 2010,Williamson et al., 2010, Walker et al., 2009; Backhaus, 2004; Cober et al ., 2004) discussed in the literature on the employer brand using career websites reveals a purely 
quantitative orientation (use of correlation and regression analysis, cluster analysis) stemming from a holistic positivist paradigm which creates a dearth of qualitative research and gap which the current study has made an attempt to address by adopting a qualitative approach. More so, in contrast to previous studies, the current study contributes to the e-recruitment literature by providing an HR practitioners' perspective to the communication of the employer brand having as vehicle the career website. Given the existing dearth of research on the HR professionals' views and perceptions on the dissemination of the employer brand through the career website, this study presents immense benefits to the HR profession. In the first instance, it is an encouragement to make use of the career website to publicize the employer brand. Secondly the whole organization as an entity will be involved to ensure the honest communication of the corporate values and culture through the employer brand thereby embracing the signaling theory (Spence, 1973; Connelly et al., 2011; Bangerter et al., 2012; Celani and Singh 2011) as strongly recommended by (Vinayak et al.,2017) for effective talent attraction, engagement and retention.

\section{Limitations}

This qualitative study was not immune to limitations. Data were obtained from only HR professionals from a single sector which may limit the ability to generalize the findings to a wider spectrum of organizations and industries. Compounding this limitation is the fact that the chosen sector was the one mostly affected by the tarnished reputation of the HR profession as an aftermath of the GFC (Jenkins and Goff, 2012). Nonetheless, the study was restricted to the banking sector and HR practitioners' perspective. Certain banks are still skeptical regarding their EB strategy and therefore some participants were hesitant to provide factual comments on its dissemination through the career websites. As a result, the HR professionals have been quite thrifty to share their views on the communication of total rewards having the corporate recruitment website as vehicle. Nevertheless given the fact that successful EB relies on departmental collaboration (Minchington, 2014), the views of the other departmental managers such as MBS marketing and communications professionals have not been considered, mostly due to the dearth of research from an HR professionals' perspective as previously pointed out.

\section{Future research directions}

It would be interesting to investigate the views of the external talent pool potential applicants on the attractiveness of the career websites in terms of the five total rewards components followed 
by a study on the views of the internal talent pool on the career website not only HR staff. Consideration can also be given to other industry sectors as well. Moreover, the views of communications and marketing staff on their contribution to the career websites will also be beneficial. As a result, it would be interesting to get the views marketing and communications professionals on the use of the career website for the communication of the employer brand which can be taken up as future research directions. Thus, it would be interesting to have the views of the marketing and communication staff on the specific design requirements of the career website to effectively portray the employer brand. Furthermore it is also imperative to gather the views of senior management on the use of career websites for competitiveness and differentiation and its impact on the corporate reputation and image of the entity. 


\section{References}

Amine, M. A, Abdellatif C and Anass M. A (2013), "Corporate Ethical and Social Responsibility and Relationship Marketing: A Content Analysis of the Websites of Moroccan Commercial Banks" International Journal of Business and Management; Vol. 8, No. 3 pp 71-102

Backhaus, K.B (2004), "An exploration of corporate recruitment descriptions on monster.com", Journal of business communication, Vol. 41, No. 2, pp115-136

Ballafkih,H., Zinsmeister, J., Meerman,M (2017), "A Job and a Sufficient Income Is Not Enough: The Needs of the Dutch Precariat" Journal of Workplace Rights SAGE Open

Bangerter, A., Roulin, N., and König, C. J. (2012), Personnel selection as a signaling game. J. Appl. Psychol. 97, 719-738. doi: 10.1037/a0026078

Baum M, Kabst R (2014), "The effectiveness of recruitment websites: Indirect and interactive effects on applicant attraction", Human Resource Management Wiley Periodicals , Inc

Berthon P, Ewing M, Lian Hah Li (2005), " Captivating company dimensions of attractiveness in EB" International journal of advertising, 24(2), pp151-172

Bondarouk T, Hub R, Elena A, Roxana A (2013), "What Is the Future of Employer Branding through Social Media? Results of the Delphi Study into the Perceptions of HR Professionals and Academics" Social Media in Human Resources Management Advanced Series in Management, pp 23-57

Bondarouk T, Hub R, Elena A, Roxana A (2014), "What Is the Future of EB through Social Media? Results of the Delphi Study into the Perceptions of HR Professionals and Academics" Social Media in Human Resources Management Advanced Series in Management, pp 23-57

Bouton, K (2015), "Recruiting for Cultural Fit" Harvard Business Reviewhttps://hbr.org/2015/07/recruiting-for-cultural-fit

Braddy P.W, Meade A.W, Kroustalis C.M (2008), "Online recruiting: the effects of organizational familiarity, website usability, and website attractiveness on viewers' impressions of organisations" Computers in Human Behaviour Elsevier 24 pp 2992-3001 
Brandão C Morais,C Dias,S Mário ,R (2017), Using Online Recruitment: Implicit Theories and Candidates' Profile Recent Advances in Information Systems and Technologies, pp.293-301 Chapter in Advances in Intelligent Systems and Computing · DOI: 10.1007/978-3-319-565415_30

Braun, V. and Clarke, V. (2006), "Using thematic analysis in psychology". Qualitative Research in Psychology, 3 (2), pp 77-101. ISSN 1478-0887

Bravo R., Pina J., M., Matute J (2011), "Communicating Spanish banks' identities: the role of websites": Online Information Review Vol. 36 No. 5, pp 675-697

Bravo R., de Chernatony L., Matute J., Pina J.M (2012), "Projecting banks' identities through corporate websites: A comparative analysis of Spain and the United Kingdom" Journal of Brand Management pp 1-25

Cable D.M and Turban D.B (2001), "Establishing the dimensions, sources and value of job seekers' employer knowledge during recruitment" Research in Personnel and Human Resources Management, Volume 20, pages 115-163.

Cable D.M and Turban D.B (2003), "The value of organizational reputation in the recruitment context: A Brand-Equity perspective", Journal of Applied social psychology, 33, 11 pp 22442266

Cable, D M.; Yu, K Y T (2006), "Managing job seekers' organizational image beliefs: The role of media richness and media credibility". Journal of Applied Psychology, Vol 91(4), 828-840

Celani A, Singh P (2011), "Signalling theory and applicant attraction outcomes", Personnel review Vol.40 No.2, pp 222-238

Charmaz, K. (2014), Constructing grounded theory (2nd ed.). Thousand Oaks, CA: Sage.

Chunyan Xie Richard P. Bagozzi Kjersti V. Meland, (2015),"The impact of reputation and identity congruence on employer brand attractiveness", Marketing Intelligence and Planning, Vol. 33 Iss 2 pp. 1-35 
CIPD and Mercer (2010), "Understanding the links between employer branding and total reward: An overview of our research findings and the implications for reward"

Cober R.T., Brown D.J, Keeping L.M., Levy P (2004), "Recruitment on the Net: How do organizational web site characteristics influence" Journal of Management 30(5) pp 623-646

Cober R.T., Brown D.J, Levy P.E (2004), "Form, content and function: an evaluative methodology for corporate employment websites" Human Resource Management, vol.43 No.2 and 3, pp 201-218

Collins , C. J (2007), "The interactive effects of recruitment practices and product awareness on job seekers' employer knowledge and application behaviours". Journal of Applied psychology, 92, $180-190$

Connelly, B. L., Certo, S. T., Ireland, R. D., and Reutzel, C. R. (2011), Signaling theory: a review and assessment. J. Manage. 37, 39-67.doi: 10.1177/0149206310388419

Dineen B.R., Williamson I.O (2012), "Screening-oriented recruitment messages: antecedents and relationships with applicant pool quality" Human Resource Management, Vol. 51, No. 3. Pp. $343-360$

Scialpi D, (2016), Employer Branding Revolution http://www.employerbrandingrevolution.com Fusch, P. I., \& Ness, L. R. (2015), “Are we there yet? Data saturation in qualitative research". The Qualitative Report, 20(9), 1408-1416. Retrieved from http://www.nova.edu/ssss/QR/QR20/9/fusch1.pdf

Gardner W.L, Reithel B.J, Cogliser C.C, Walumbwa F.O Foley R.T (2012), "Matching personality and organizational culture: Effects of recruitment strategy and the five-factor model on subjective person-organization fit", Management communication Quarterly, issue 26(4), pp585-622.

Gatewood, R.D., Gowan, M.A., and Lautenschlager, G.J. (1993), Corporate image, recruitment image, and initial job choice decisions. Academy of Management Journal, 36, 414-427

Gilani H, Jamshed S, (2016), "An exploratory study on the impact of recruitment process outsourcing on employer branding of an organisation", Strategic Outsourcing: An International Journal Vol 9 Issue: 3, pp.303-323 
Glaser, B., \& Strauss, A. (1967), The discovery of grounded theory. Chicago: Aldine

Harquail C.V. (2009), "Don't let personal branding stifle your authentic voice", Available at: http://authenticorganizations.com/harquail/2009/06/09/dont-let-personal-branding-stifle-yourauthentic-voice/

Hess, J.S., Kellman, I (2017), "Tourism Industry Financing of Climate Change Adaptation: Exploring the Potential in Small Island Developing States" Climate, Disaster and Development Journal Volume 2 Issue 2 pp34-45

Hinson R, Boateng R, Madichie N, (2010),"Corporate social responsibility activity reportage on bank websites in Ghana", International Journal of Bank Marketing, Vol. 28 Iss: 7 pp. 498 - 518

Hooley T, (2017),"Developing your career: harnessing the power of the internet for "digital career management" ", Development and Learning in Organizations: An International Journal, Vol. 31 Iss 1 pp. $9-11$

Hu, C., Su, H., Chen ,C.B (2009), " The effect of person-organisation fit feedback via recruitment websites on applicant attraction" Computers in Human Behaviour, issue 23 pp 2509-2523

Hurrell S.A, Scholarios (2013), "The people make the brand": Reducing social skills gaps through person-brand fit and human resource management practices" Journal of service research pp 1-14

Jenkins P, Goff S (2012), "Barclays tension with FSA laid bare" Financial times www.ft.com Jothi V (2010), "HR marketing" recruiting blogs .com

Kemp, Linzi J., Zhao, F (2016), "Influences of cultural orientations on Emirati women's careers", Personnel Review, Vol. 45 Issue: 5, pp.988-1009,

Khan T.N (2017), "Evaluating Saudi corporate companies' online recruitment." Journal of Business Theory and Practice, volume 5 number 1 
Krippendorff, K. H. (2012), Content analysis: An introduction to its methodology (3rd ed.). Los Angeles, CA: Sage.

Kristof-Brown A.L (2000), "Perceived applicant fit: distinguishing between recruiters' perceptions of person-job and person-organisation fit" Personnel psychology Vol.53 pp 643-671.

Kroustalis, C. M., and Meade, A.W. (2007), "Portraying an organization's culture through properties of a recruitment website". Paper presented at the 22nd Annual Meeting of the Society for Industrial and Organizational Psychology, New York.

Kucherov, D., Samokish, V (2016), "Employer brand equity measurement", Strategic HR Review, Vol. 15 Issue: 1, pp.29-33,

Ladkin, A., Buhalis, D, (2016), "Online and social media recruitment: Hospitality employer and prospective employee considerations", International Journal of Contemporary Hospitality Management, Vol. 28 Issue: 2, pp.327-345,

Landers, R.N. and Schmidt, G.B. (Eds) (2016), Social Media in Employee Selection and Recruitment,Springer International Publishing, Cham.

Lee I (2005), "The Evolution of E-Recruiting: A Content Analysis of Fortune 100 Career Web Sites" Electronic commerce in organisations", Vol.3, Issue 3, pp 57-68

Lievens, F., Van Hoye, G. and Anseel, F. (2007), “Organizational Identity and Employer Image: Towards a Unifying Framework". British Journal of Management, 18: S45-S59.

Lincoln, Y. S. \& Guba, E. G. (1985). Naturalistic inquiry. Beverly Hills, CA: Sage.

Lukea Bhiwajee, S ., Garavan, T.N. (2016), "The empowering of public sector officers in the Mauritian public sector in the context of reforms: How far has management education helped?", European Journal of Training and Development, Vol. 40 Issue: 4, pp.262-283

Marcel J.Hvan Birgelen, Martin G.M ,Wetzels Willemijn M.van Dolen (2008), Effectiveness of corporate employment websites", International journal of manpower, vol29 Iss 8 pp. 731-751

Martin G, Gollan P, Grigg K (2009), "A future for employer branding? Dealing with negative capabilities in Strategic Human Resource Management" IRA HRM study group working papers in Human Resource Management. 
Martin, G., and Groen-in't-Woud, S. (2011), "EB and corporate reputation management in global companies: a signaling model and case illustration" In: Scullion, H. and Collings, D. (eds.) Global Talent Management. Routledge, London, pp. 87-110. ISBN 9780415871709

Mason, M (2010), Sample Size and Saturation in PhD Studies Using Qualitative Interviews Forum Qualitative Sozialforschung / Forum: Qualitative Social Research, 11(3), Art. 8, http://nbn-resolving.de/urn:nbn:de:0114-fqs100387.

Mauritius bankers association (2014), Profile of Banks 2014 Edition

McDonald, P. and Thompson, P. (2016), "Social media (tion) and the reshaping of public/private boundaries in employment relations", International Journal of Management Reviews, Vol. 18 No. 1,pp. 69-84.

Minchington B (2009), "Employer Branding global research study", Employer brand Institute, www.employerbrandinstitute.com

Michington B (2010), "Employer brand research shows key trends HR Future International Waters Global Master class"

Minchington B (2013), "EB Global Insights Research Study Report", www.employerbrandinginternational.com

Minchington B (2014), "EB Global Trends Study Report" www.employerbranding international.com.

Miles, M.B. and Huberman, A.M. (1994), Qualitative Data Analysis, Sage, Thousand Oaks, CA. Nazir N (2005) "Person-Culture Fit and Employee Commitment in Banks" Vikalpa volume 30 no 3

Novak ,J (2017), "Making the cut when applying for jobs online" Journal of Vocational Rehabilitation 46 pp 293-299 DOI:10.3233/JVR-170864 IOS Press 293

Oladipo T, lyambo J, Otubanjo (2013), “EB: moulding desired perceptions in current and potential employees" Journal of management and sustainability, vol 3 no.3 pp 55-65 
Parry, E., Wilson, H (2009), "Factors influencing the adoption of online recruitment", Personnel Review, Vol. 38 Issue: 6, pp.655-673,

Priyadarshini, C., Kumar, Y., \& Jha, R. R. (2017), Employer Attractiveness Through Social Media: A Phenomenological Study.The Qualitative Report, 22(4), 969-983. Retrieved from http://nsuworks.nova.edu/tar/vol22/iss $4 / 3$

Priyadarshini, C.. Sreejesh S, Anusree, M.R (2017), "Effect of information quality of employment website on attitude toward the website: A moderated mediation study", International Journal of Manpower, Vol. 38 Issue: 5, pp.729-745, https://doi.org/10.1108/IJM-12$\underline{2015-0235}$

Ryan A.M., Sacco J.M., Mc Farland L.A., Kriska S.D (2000), "Applicant self-selection: Correlates of withdrawal from a multiple hurdle process"

Schlechter A, Thompson N, Bussin M, (2015),"Attractiveness of Non-Financial Rewards for Prospective Knowledge Workers: An Experimental Investigation", Employee Relations: The International Journal, Vol. 37 Iss 3 pp. 1 -27

Scialpi, D (2016), "The role of Person-Organization fit in Employer Branding" https://medium.com/@davidescialpi/guest-post

Singh, S (2017) "E-Recruitment: A New Dimension of Human Resource Management in India" International Journal of Advance Research in Computer Science and Management Studies Volume 5 , Issue 3

Sivertzen, A.M., Nilsen, E.R., Olafsen A.H (2013), "Employer branding: employer attractiveness and the use of social media" Journal of product and brand management vol 22 No.7pp473-483

Spence, M. (1973). Job market signaling. Q. J. Econ. 87, 355-374. doi: 10.2307/18 82010

Srinivasta S.C., Teo T.S.H., Subramanian A.M ( 2009), "Rational versus institutional perspectives in organizational websites" Communications of the associations for information systems Vol.24 No.36, pp 615-638 
Strauss, A., \& Corbin, J. (1998), Basics of qualitative research. Thousand Oaks, CA: Sage.

Tanwar,K, Prasad,A , (2017)," Employer brand scale development and validation: a second order factor approach ", Personnel Review, Vol. 46 Iss 2 pp. $389-409$

Towers Watson (2013), "Creating a Sustainable Employment Deal: Getting EVP and Total Rewards Right", Global Talent Management and Rewards Study2012 - 2013.

Thompson L.R, Braddy P.W, Wuensch K.L (2008), "E-recruitment and the benefits of web appeal" Computers in Human Behaviour 24 Science direct Elsevier

Universum Global (2014), "Talent can now choose their employers. Did they choose you as World's Most Attractive?"

Van Idekinge, C.H., Lanivich S.E., Roth,P.L., Junco, Elliott (2016), "Social Media for Selection? Validity and Adverse Impact Potential of a Facebook-Based Assessment" Journal of Management Vol. 42 No. 7

Vinayak, P.C., Khan B.M., Jain, M.C (2017) "Role of Signalling Theory in Potential Applicant Attraction: An Employer Branding Perspective" International Journal of Emerging Research in Management \&Technology ISSN: 2278-9359 (Volume-6, Issue-4)

Walker H. J., Feild Hubert S., Giles William F, Achilles A. Armenakis, Bernerth J B (2009), "Displaying Employee Testimonials on Recruitment Web Sites: Effects of Communication Media, Employee Race, and Job Seeker Race on Organizational Attraction and Information Credibility." Journal of Applied Psychology American Psychological Association, Vol. 94 No. 5, pp 1354-1364

Welsing-Boogard-Boogard, C (2006),HRMarekting: A new perspective on Human Resources Management. Financial Times, Prentice Hall, pearson education, ISBN-13 978-90-430, 1340-6

Williamson I.O., King J.E., Lepak D (2003), "The effect of company recruitment web site orientation on individuals' perceptions of organizational attractiveness" Journal of vocational behavior Vol.63, pp 242-263

Williamson I.O., King J.E., Lepak D., Sharma A (2010), "Firm reputation, recruitment websites and attracting applicants" Human resource management, Vol.49 No.4 pp 669-687. 
World at work (2010), "The relative influence of total rewards elements on attraction, motivation and retention".

Yin, R. K. (1994), Case Study Research Design and Methods. Newbury Park, CA: Sage.

Young J and Foot K (2005), "Corporate E-cuiting: The construction of work in Fortune 500 recruiting websites". Journal of computer-mediated communication, 11(1)

Yin, R.K. (2013), Case Study Research: Design and Methods, Sage publications, Thousand Oaks, CA.

Zamparini, Calegari and Lurati (2010), "Message Effectiveness in Corporate Career Websites Analysis of the Top 30 Employers in Switzerland", IMCA Working Papers Number 1Università della Svizzera italiana, Lugano pp 2-36 
Figure 1: conceptual framework

\section{Career website}

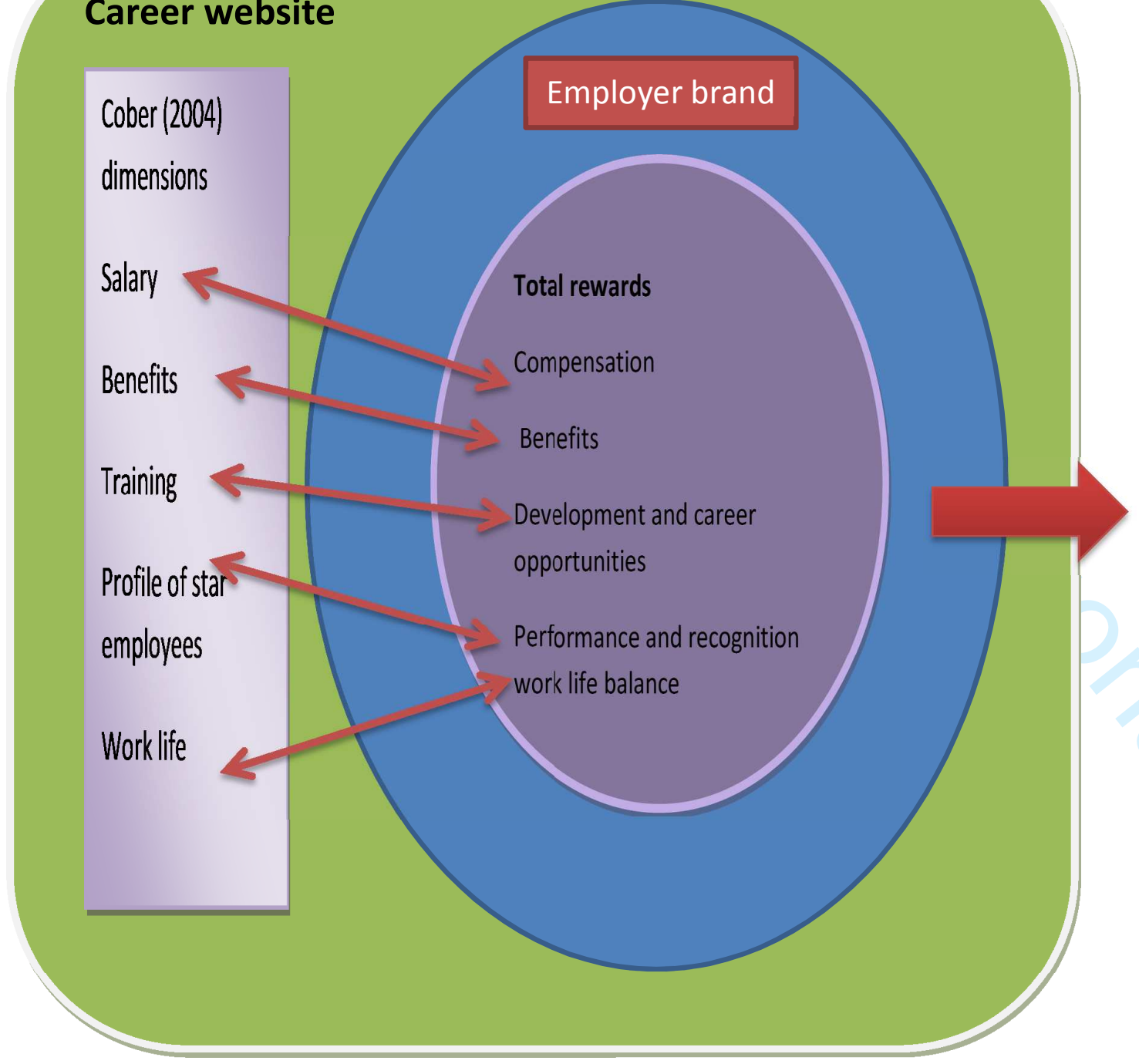

Strategic talent relationship management

Talent attraction

Talent engagement

Talent retention 
Table 1: Participants' profile

\begin{tabular}{|c|c|c|}
\hline Participant No./bank status & Job title & $\begin{array}{c}\text { Years of } \\
\text { experience in HR } \\
\text { profession } \\
\text { banking sector }\end{array}$ \\
\hline P1 MNE HQ India A & Manager HR/Administration & 26 \\
\hline P2 MNE HQ India B & HR manager & 14 \\
\hline P3 MNE HQ France & HR manager & 13 \\
\hline P4 MNE HQ South Africa & Head of HR & 25 \\
\hline P5 MNE HQ South Africa & HR officer & 3 \\
\hline P6 MNE HQ UK A & Resourcing manager & 14 \\
\hline P7 MNE HQ UK A & Reward Manager & 4 \\
\hline P8 MNE HQ UK A & Head of HR & 16 \\
\hline P9 MNE HQ UK B & HR manager & 16 \\
\hline P10 MB 1 & $\begin{array}{l}\text { HR position customer service } \\
\text { representative }\end{array}$ & 4 \\
\hline P11 MB 2 & Head of HR and Change & 4 \\
\hline P12 MB 3 & HR Consultant & 15 \\
\hline P13 MB 4 & HR Head & 3 \\
\hline P14 MB 5 & Vice President of Finance & $\begin{array}{l}2 \text { years in } \mathrm{HR}, 14 \\
\text { years in Financial }\end{array}$ \\
\hline P15 MB 6 & $\begin{array}{l}\text { Group Head of Human } \\
\text { Resources }\end{array}$ & 30 \\
\hline P16 MB 6 & Learning and Talent Manager & 8 \\
\hline P17 MB 6 & HR operations Manager & 9 \\
\hline
\end{tabular}




\begin{tabular}{|l|l|c|}
\hline P18 MB 6 & \multicolumn{1}{|l|}{ Rewards \& benefits Manager } & 21 \\
\hline P19 MB 6 & HR services Manager & 14 \\
\hline P20 MB 6 & $\begin{array}{l}\text { Talent Management } \\
\text { Specialist }\end{array}$ & 12 \\
\hline P21 MB 6 & $\begin{array}{l}\text { Talent Management } \\
\text { Specialist }\end{array}$ & 12 \\
\hline P22 MB 6 & $\begin{array}{l}\text { Talent Management } \\
\text { Specialist }\end{array}$ & 17 \\
\hline P23 MB 6 & $\begin{array}{l}\text { Talent Management } \\
\text { Coordinator }\end{array}$ & 14 \\
\hline P24 MB 6 & Talent Management \\
\hline P25 MB 6 & Coordinator & 6 \\
\hline P26 MB 6 & HR Business Partner & 7 \\
\hline P27 MB 6 & HR Business Partner & 10 \\
\hline
\end{tabular}


Table 2: Thematic analysis outcome

\begin{tabular}{|c|c|c|}
\hline Theme & $\begin{array}{l}\text { Participant } \\
\text { details }\end{array}$ & Text extract \\
\hline \multirow[t]{4}{*}{$\begin{array}{l}\text { The employer } \\
\text { brand } \\
\text { communicated by } \\
\text { MBS banks' } \\
\text { career website }\end{array}$} & $\begin{array}{l}\text { P17 HR } \\
\text { operations } \\
\text { manager } \\
\text { MB6 }\end{array}$ & $\begin{array}{l}\text { More details need to be provided on the internal } \\
\text { career website and the HR team is actually working } \\
\text { on the detailed EB strategy for the career website." }\end{array}$ \\
\hline & $\begin{array}{l}\text { P20 Talent } \\
\text { management } \\
\text { specialist } \\
\text { MB6 }\end{array}$ & $\begin{array}{l}\text { "More thoughts need to be given on how the career } \\
\text { website should fully incorporate the employer brand" }\end{array}$ \\
\hline & $\begin{array}{l}\text { P4 Head of } \\
\text { HR MNE HQ } \\
\text { South Africa }\end{array}$ & $\begin{array}{l}\text { "The group career website tries to portray employer of } \\
\text { choice status and the publicizing of employer awards. } \\
\text { However no local career website has been designed } \\
\text { to date". }\end{array}$ \\
\hline & $\begin{array}{l}\text { P10 HR } \\
\text { officer MB1 }\end{array}$ & $\begin{array}{l}\text { "Internal and external recruitment depend on different } \\
\text { communication means. The external career website is } \\
\text { carefully formulated, with little and basic information. } \\
\text { Communication should aim at engaging talents to the } \\
\text { employer brand". }\end{array}$ \\
\hline \multirow[t]{2}{*}{$\begin{array}{l}\text { The need for } \\
\text { career website } \\
\text { revamping }\end{array}$} & $\begin{array}{l}\text { P7 Rewards } \\
\text { manager } \\
\text { MNE HQ UK } \\
\text { A }\end{array}$ & $\begin{array}{l}\text { "The career website needs a lot of revamping. It } \\
\text { should be more attractive in terms of employee } \\
\text { sharing their experiences and how easy it is for } \\
\text { applicants to apply that is in terms of user friendliness. } \\
\text { Not all components are present. However, } \\
\text { Assignment opportunities, Learning opportunities and } \\
\text { the term Competitive remuneration packages are } \\
\text { communicated". }\end{array}$ \\
\hline & $\begin{array}{l}\text { P8 Head of } \\
\text { HR MNE HQ } \\
\text { UK A }\end{array}$ & $\begin{array}{l}\text { "The recently revamped career website would reflect } \\
\text { the employer branding strategy. It will also exhibit } \\
\text { success stories through employee testimonials. } \\
\text { Career opportunities offered provides the ability to see } \\
\text { global opportunities. The total rewards components }\end{array}$ \\
\hline
\end{tabular}




\begin{tabular}{|c|c|c|}
\hline & & $\begin{array}{l}\text { are not yet displayed. Only general information is } \\
\text { available on the local career website, however, the } \\
\text { global career website offers more detailed } \\
\text { information". }\end{array}$ \\
\hline & $\begin{array}{l}\text { P7 Rewards } \\
\text { manager } \\
\text { MNE HQ UK } \\
\text { A }\end{array}$ & $\begin{array}{l}\text { "The career website needs a lot of revamping. It } \\
\text { should be more attractive in terms of employee } \\
\text { sharing their experiences and how easy it is for } \\
\text { applicants to apply that is in terms of user friendliness. } \\
\text { Not all components are present. However, } \\
\text { Assignment opportunities, Learning opportunities and } \\
\text { the term Competitive remuneration packages are } \\
\text { communicated". }\end{array}$ \\
\hline $\begin{array}{l}\text { Career websites } \\
\text { displaying the } \\
\text { total reward } \\
\text { component of the } \\
\text { employer brand }\end{array}$ & $\begin{array}{l}\text { P5 HR officer } \\
\text { MNE HQ } \\
\text { South Africa }\end{array}$ & $\begin{array}{l}\text { Brief mention of work-life balance, performance and } \\
\text { career development appear on the career website." }\end{array}$ \\
\hline & $\begin{array}{l}\text { P24 Talent } \\
\text { management } \\
\text { coordinator } \\
\text { MB6 }\end{array}$ & $\begin{array}{l}\text { "General information on Total rewards are displayed } \\
\text { on the career website." }\end{array}$ \\
\hline & $\begin{array}{l}\text { P15 Group } \\
\text { Head of HR } \\
\text { MB6 }\end{array}$ & $\begin{array}{l}\text { The total rewards components have not yet been fully } \\
\text { included on the career website." }\end{array}$ \\
\hline & $\begin{array}{l}\text { P4 Head of } \\
\text { HR MNE HQ } \\
\text { South Africa }\end{array}$ & $\begin{array}{l}\text { These details about the compensation and benefits } \\
\text { components of total rewards are quite confidential and } \\
\text { are thus not communicated on the career website" }\end{array}$ \\
\hline
\end{tabular}

